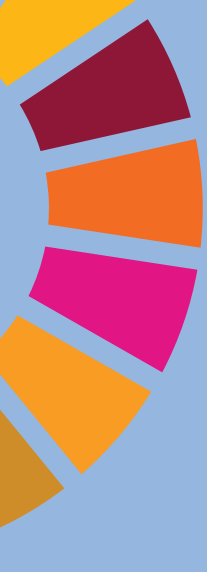

\title{
REFLEXIONES SOBRE EL ESTADO DE LA FINANCIACIÓN SOSTENIBLE EN ESPAÑA
}

\section{THOUGHTS ON THE STATE OF SUSTAINABLE FINANCING IN SPAIN}

\author{
Julián Romero Zarco \\ Observatorio español de la financiación sostenible \\ julianromero@ofiso.es
}

\section{RESUMEN:}

Podemos decir que la contribución de España al desarrollo de las finanzas sostenibles ha sido muy destacada. El fuerte crecimiento de este mercado se ha desencadenado en la segunda parte de la pasada década y España se consolida entre los diez mayores países que toman prestado dinero para proyectos con credenciales positivas para el medioambiente o con fines sociales destinados a colectivos desfavorecidos. Basados en el Informe Anual publicado por Ofiso en los dos últimos años, trato de identificar algunos de los motivos de esta situación, algunas claves que ayudan a entender las particularidades de nuestro país en este ámbito y los retos que se deberán afrontar en el futuro.

Palabras clave. Bonos; Préstamos; Bonos-verdes; Bonos-sociales; Préstamos-verdes; Financiación, Sostenible.

\section{SUMMARY}

We can say that Spain's contribution to the development of sustainable finance has been very prominent. The strong growth of this market has been unleashed in the second part of the last decade and Spain is consolidated among the ten largest countries that borrow money for projects with positive credentials for the environment or for social purposes for disadvantaged groups. Based on the Annual Report published by Ofiso in the last two years, I try to identify some of the reasons for this situation, some keys that help to understand the particularities of our country in this area and the challenges to be faced in the future.

Keywords: Bonds; Loans; Green-bonds; Social-bonds; Green-loans; Financing; Sustainable. 
Julián Romero es actualmente Presidente del Observatorio español de la Financiación Sostenible. Es licenciado en CC. Económicas por la Universidad Complutense de Madrid. Posee un diploma en Banca Responsable por el IEB y un curso en Desarrollo Sostenible por la Universidad de Columbia.

En 2005, se convierte en responsable para Europa de Sindicación de bonos en BBVA. En 2017, crea el área de Bonos Sostenibles en dicho Banco. Testigo del nacimiento y evolución de los mercados de bonos verdes, ha sido el representante de su entidad en los Green Bond Principles desde 2014.

Cuando te propones por primera vez la evaluación de una materia que por su naturaleza se encuentra en las primeras fases de evolución, resulta complejo sacar conclusiones. Particularmente, si se trata de hacerlo a partir de fotos fijas de un periodo de tiempo limitado como el mes, el trimestre o el año y además circunscribir el análisis a un área geográfica concreta con importantes solapamientos con tu entorno más próximo. Todo lo cual requiere una continua búsqueda de las fronteras donde delimitar dicho análisis.

La escasez de datos públicos por un lado, y los diferentes métodos de selección de los datos privados por otro, incrementan la dificultad de conseguir resultados definitivos y, en todo caso, de realizar comparaciones con pares. En un ámbito donde uno de los fundamentos de su razón de ser es la transparencia no deja de ser paradójico que el acceso a los datos tenga un marcado carácter privado. Señalaremos más adelante dónde algunos cambios en este sentido son más acuciantes.

Tras dos años consecutivos realizando el Informe Anual sobre la Financiación Sostenible en España, podemos extraer algunas reflexiones interesantes sobre su estado actual, las bases que han permitido llegar a la situación actual y los retos a los que se enfrenta para continuar evolucionando.

Probablemente la constatación de que la financiación sostenible en el mercados de capitales en España ha superado el $10 \%$ del total, ha sido la que nos da una mejor idea del peso que ha alcanzado este sector en nuestro país.

Es cierto que el mercado de capitales supone entorno al $45 \%$ del total de la financiación sostenible y, por tanto, es complicado la extrapolación al total. Pero sí podemos afirmar que ese porcentaje dobla a la cifra global, lo cual le infiere un carácter muy positivo al número español.

Es muy cierto que este primer dato da sentido a los datos que año tras año sitúan a España en el grupo destacado de los 10 mayores emisores de Bonos Verdes del mundo. Climate Bond Initiative (CBI) publica esta cifra en sus informes anuales y se ha visto también confirmado cuando el volumen de estos activos ha alcanzado el primer trillón de dólares. Según CBI habría contribuido con 34 billones de dólares, sería el quinto contribuidor de Europa, detrás de Francia, Alemania, Holanda y Suecia y el séptimo a nivel mundial al incluir en la lista a EE.UU. y a China, que ocupan la primera y segunda posición a nivel global.

Son varios los motivos que pueden aducirse para entender la posición destacada de nuestro país en el contexto de la financiación sostenible internacional. La internacionalización de muchas de nuestras compañías, la profesionalización de sus equipos de financiación, la buena reputación de sus credenciales en el mercado son todos factores que han ayudado. Asimismo, creo que ha ayudado el éxito de la participación de algunos pioneros como Iberdrola, primer emisor nacional de Bonos Verdes en abril de 2014 y que a día de hoy se consolida como el mayor grupo emisor de Bonos Verdes a nivel mundial, el Instituto de Crédito Oficial (ICO) como impulsor del estándar de Bonos Sociales y uno de los primeros emisores a nivel mundial de esta categoría en enero de 2015. Y el empuje de BBVA en el asesoramiento a los emisores en los mercados sostenibles desde su primera operación en mayo del 2014. 
El dato del $10 \%$ de la financiación total ofrece una muy buena indicación, pero en términos absolutos la indicación es más dudosa. No sabemos cuál sería el porcentaje ideal o el número a alcanzar, y tampoco podemos saber qué parte del $90 \%$ restante es susceptible de recanalización hacia proyectos compatibles con la sostenibilidad. Esto abre una oportunidad para profundizar en la recolección de información que aporte luz a esas interrogantes.

Una vez contextualizada la participación relativa y advertidas sus limitaciones, vamos a ver cómo está repartido entre los diferentes productos financieros mayoritariamente utilizados: bonos y préstamos.

Como decíamos anteriormente, el peso de los Bonos es del 45\%, con un volumen absoluto que ha superado los 15.000 millones de euros. La distribución por tipo de bonos ha sido del $61 \%$ para los bonos verdes, $19 \%$ para los sociales y $20 \%$ para los sostenibles. A pesar del enorme crecimiento de los Bonos sociales a nivel global, lo cierto es que España, dada su estructura de emisores con fuerte presencia del sector público, apenas han reducido un $4 \%$ el peso relativo de los Bonos verdes, y es la cifra global la que ha convergido fuertemente hacia el modelo español, descendiendo desde el $82 \%$ de 2019 hasta el 57\% en 2020, en su modalidad verde.

La pandemia sin duda ha tenido efectos muy considerables sobre la evolución del 2020. La más conocida sin duda es el efecto sobre la emisión de bonos sociales, y su enorme utilización para la canalización de los diversos paquetes nacionales de ayuda. Pero ha habido un segundo efecto importante, la caída absoluta del volumen nominal de préstamos con etiqueta sostenible.

Bloomberg cifra esta caída internacional en un 22\%, mientras en España nuestra observación de la caída nos lleva al 13\%. Parece lógica, que una caída del PIB histórica de doble dígito, haya afectado significativamente a la demanda de fondos, y pensamos que se ha realizado en una doble dimensión. Durante la primera parte del año y ante la fortísima reacción de los mercados a la primera ola de la pandemia, las empresas acudieron a productos que les protegiesen de posible estrecheces de liquidez vía facilidades de crédito, mientras en un segunda parte del año, la exuberancia del mercado de bonos alimentada por la reafirmación de los programas cuantitativos de los bancos centrales ha producido un cierto trasvase entre una y otra modalidad de financiación.

Significativo ha sido que toda la caída de la actividad en préstamos se ha centrado en la modalidad de préstamos ligados a la sostenibilidad (-24\%) que venía creciendo a ritmos muy altos dada su flexibilidad y novedad, también cifrada en el contexto anterior.

Sin embargo, en nuestro análisis seguimos incorporando la financiación para proyectos que aun sin estar alineados a ningún estándar ni auto etiquetarse como verde, corresponden a inversiones que en su práctica totalidad se consideran sostenibles. Me refiero a la modalidad de financiación de proyectos, donde de nuevo este año ha habido un sector ganador el de la inversión en energías renovables. El crecimiento de esta modalidad de préstamos en 2020 ha sido del $230 \%$ y su peso en el total de préstamos ya es del $50 \%$ que, por extensión, supondría el 28\% del total de la financiación sostenible en España.

En todo caso, esperamos y deseamos que las circunstancias cambien en el 2021 y que los préstamos vuelvan a recuperar tasas de crecimiento en consonancia con el de las finanzas sostenibles en general.

Sectorialmente, los proyectos de energía renovables ocupan la primera posición, seguido del sector inmobiliario, sector ausente en el mercado de bonos y tras ellos el sector del comercio minorista, aunque esta anomalía se concentra en una única operación de 2000 millones de euros de El Corte Inglés. 
Es necesario hacer dos apuntes en relación al mercado de préstamos, que tiene un carácter alto de privacidad, y por tanto, está sujeto a incentivos económicos diferentes al de los bonos. Deben explorarse soluciones que aumenten la transparencia. Por un lado, es necesario registrar las operaciones, con los mayores datos posibles que permitan clasificarlos y después agregarlos y ordenarlos, aun sabiendo que los proveedores de datos por el momento son privados. Por otro lado, han de ofrecer información suficiente sobre su aportación a la sostenibilidad capaz de generar confianza y en consecuencia, ayuden a identificar activos sostenibles. De lo contrario existe el riesgo, tanto para los prestamistas como para los prestatarios, de generar sospechas sobre la ambición de sus actividades, e incluso, aún peor sobre prácticas de greenwashing.

Tras el mercado de préstamos, ahora veamos algunos datos relacionados con el mercado de capitales sobre los que reflexionar.

Uno de ellos, que sorprendió este último año, es el de ver a cuatro intermediarios españoles entre los cinco más activos. En el 2019 sólo BBVA y Santander estaban en el grupo que junto a HSBC se repartían las tres primeras posiciones. Sin embargo, este año Banco de Sabadell y CaixaBank, se han incorporado, dejando a intermediarios europeos en posiciones menos destacadas. Esto es un fuerte indicador de la creciente atención y disponibilidad de recursos que las entidades nacionales están dedicando al mercado de las finanzas sostenibles.

Más tímidamente, hemos observado esta tendencia en los verificadores o certificadores de las credenciales sociales o medioambientales de esos bonos. Sigue habiendo en este sentido una fuerte concentración de consultoras, si bien hemos visto empresas locales empezando a participar especialmente en préstamos corporativos. En todo caso la ampliación de la competencia nos parece una señal positiva para ganar eficiencia en este tipo de operaciones.

En cuanto al uso de los fondos es preciso señalar el fuerte peso de las energías renovables en el uso de los fondos, dato que corrobora también el liderazgo de nuestro país en esta categoría. En segundo lugar, aparece la movilidad sostenible con un $19 \%$, dejando a los proyectos de eficiencia energética en un tercer lugar con un $13 \%$. Sorprende la ausencia de proyectos para edificación residencial o industrial sostenible, que a nivel internacional supone la segunda categoría de proyectos con mayor financiación. Además, hay que señalar que el estudio debe profundizar en el uso de los fondos de los bonos sociales y sostenibles que seguro que añadirán más sensibilidad a la información del sistema. En ese sentido, abogaremos por un mayor detalle por parte de algunos emisores en la información previa a la emisión.

Atendiendo al tipo de emisor, cabe destacar el aumento del peso de los emisores financieros que en solo tres años han pasado del $17 \%$ del total a ser el grupo mayoritario en el 2020 , con un $43 \%$ del total emitido. Este crecimiento se ha producido a costa del sector corporativo, ya que el peso del sector público, en el caso español, mayoritariamente el ICO y las CC. AA., se ha mantenido estable entre el $30 \%$ y el $35 \%$. Sin riesgo a equivocarnos, prevemos que esto se verá sustancialmente modificado por la entrada del Tesoro Público español como emisor en este mercado, como ha anunciado, en el segundo semestre de este año.

Una última reflexión sobre la aparición de operaciones de financiación destinadas a la parte operativa de las compañías o working capital. Ya habíamos visto anteriormente, operaciones de avales o garantías, algunas de leasing, pero singularmente las de confirming, o reverse factoring, las encontramos de suma importancia por su capacidad de influir en la alineación con objetivos medioambientales, e incluso sociales o de gobernanza de los proveedores, a lo largo de toda la cadena de valor de una actividad económica determinada. 
La extraordinaria evolución en los últimos pocos años del mercado permite ser muy optimista sobre su futuro crecimiento y acerca de la innovación en productos ya que esperamos ver el primer bono ligado a la sostenibilidad en España, nuevas titulizaciones, acceso de emisores al mercado de capitales, operaciones transaccionales, etc. Pero sin duda, el gran catalizador será la nueva regulación que va a afectar muy sensiblemente y en primer lugar a los asesores, managers y propietarios de activos financieros. El salto en la calidad de la información que se les exigirá y la transparencia serán sin duda los que producirán nuevas dinámicas en el crecimiento y en la innovación. La aportación de esta información por parte de los inversores, hasta ahora limitada y poco actualizada, ayudará enormemente a la toma de decisiones bien informadas en el futuro próximo.

Probablemente sus efectos no se empezarán a notar hasta el 2022, perocon seguridad generarán importantes cambios en la asignación de capitales, que no es sino la principal aportación del sector financiero al nuevo modelo económico. 


\section{REFERENCIAS BIBLIOGRÁFICAS}

- BlombergNEF (2021). Total Breaks Annual Record Despite Covid-19 Challenges. Recuperado el 15 de abril de 2021 de https://about.bnef.com/blog/sustainable-debt-breaks-annual-record-despite-covid-19challenges/

- Climate Bond Initiative (2020). \$1Trillion Mark Reached in Global Cumulative Green Issuance: Climate Bonds Data Intelligence Reports: Latest Figures. Recuperado el 15 de abril de 2021 de https://www. climatebonds.net/2020/12/1trillion-mark-reached-global-cumulative-green-issuance-climate-bondsdata-intelligence

- Observatorio Español de la Financiación Sostenible (OFISO) (2021).Informe Anual OFISO: La financiación sostenible en España en 2020. Recuperado el 15 de abril de 2021 de https://www. climatebonds.net/2020/12/1trillion-mark-reached-global-cumulative-green-issuance-climate-bondsdata-intelligence 